\title{
Investigation of William H. Sheldon's Constitutional Theory of Personality: A Case Study of the University of the Gambia
}

\author{
Igharo 0 Kenneth \\ School of Education, The University of The Gambia \\ Bakke M.Matthew \\ Taraba State College of Agriculture, Jalingo, Nigeria \\ Member Nigeria Technical Aid Corp, attached to The University of The Gambia
}

\section{Doi:10.5901/mjss.2013.v4n7p85}

\section{Abstract}

Constitutional psychology, the theory put forth by Sheldon, refers to "the study of the psychological aspects of human behaviour as they are related to the morphology and physiology of the body." In the face of indifference or hostility to the possibility of important associations between structural and behavioural characteristics, the work of William H. Sheldon stands as a unique contribution on the contemporary scene. In general, it seems fair to say that African psychologists have tacitly less attention to the study of this important class of variables having to do with the physical description of the body. Now, it is adapted to the African Culture and environment; thus this forms the significant basis of this study. So, it is the purpose of this study to specifically ascertain the culture - environmental applicability of Sheldon's theory on personality traits in Africa. Two hypotheses drawn as follows were tested to measure relationships and differences between the body types and personality traits of individuals in the African culturally influenced community or environment. In this study we shall attempt to place Sheldon's work in brief historical perspective and then describe his formulations and investigations. A quantitative survey design was applied, with a validated 36 - item questionnaire. The questionnaire was administered to 242 (two hundred and forty two) University of The Gambia students by stratified sampling technique based on body types (whether endomorph, mesomorph or ectomorph). The physical body type an individual possesses has an influence on the behaviour or personality of that individual, as posited by Sheldon's constitutional theory. This was confirmed, even when applied in the African society specifically in The Gambia, by this study.

Keywords: Constitutional theory, Africa, somatotype, personality, Gambia

\section{Introduction}

This is a theory, which has, in its own sense dealt with how human personality forms, develops and how it influences behaviour personality of the individual. According to Hall, Calvin S. Lindzey, Gardner , (1957), because it is commonly accepted that physical characteristics are linked closely to genetic factors, the suggestion that physical and psychological characteristics are intimately related seems to imply a championing of genetic determinism. In general, it seems fair to say that African psychologists have tacitly neglected the study of that important class of variables having to do with the physical description of the body.

In the face of this indifference or hostility to the possibility of important associations between structural and behavioural characteristics, the work of William $\mathrm{H}$. Sheldon stands as a unique contribution on the contemporary scene. In this study we shall attempt to place Sheldon's work in brief historical perspective and then describe his formulations and investigations. In some respects it may seem unwise to focus so heavily upon the work of a single man when over the years so many have worked in this area. However, Sheldon's work is empirically far superior to that of his predecessors and for the contemporary psychologist it is largely 
the research of Sheldon and his collaborators that makes this investigation a topic of significance. Constitutional psychology, the theory put forth by Sheldon, refers to "the study of the psychological aspects of human behavior as they are related to the morphology and physiology of the body." (PsycINFO Database Record (c) 2010 APA,).

It is the purpose of this study to specifically ascertain the culture - environmental applicability of Sheldon's theory on personality traits in Africa, using 242 students of the University of The Gambia, The Gambia, West Africa as a case study, being that the university parades an international community of African students and faculty. Since it is adapted to the African Culture and environment; hence this forms the significant basis of this study.

Two hypotheses drawn as follows were tested to to measure relationships and differences between the body types and personality traits of individuals in the African culturally influenced community or environment.

Hypothesis $1\left(\mathrm{H}_{01}, \mathrm{a}=0.05\right)$;:There is no significant relationship between body types and the personality or behavioural traits of individual Africans.

Hypothesis $2\left(\mathrm{H}_{02}, \mathrm{a}=0.05\right)$ : There is no significant difference between body types and the personality or behavioural traits of individual Africans.

\section{Literature Review}

\subsection{Sheldon on Human Nature}

Orubu (1987), writing on WILLIAM H. SHELDON, "Sheldon's Constitutional Theory" expressed the fact that Sheldon' association with his naturalist father, the animal breeder may have probably influenced his thinking , view and values to human behaviour. Some of his works like (The Varieties of Human Physique, 1940, Varieties of Temperament, 1942; Atlas of Women and Atlas of Children, 1977) all represent an attempt at identifying and explaining human nature and behaviour in terms of body components.

Sheldon believes that the individual is conscious of his/her actions. In other words, the individual is a rational being. Sheldon, disagreeing that individual are not controlled by the id, ego and super ego as psychoanalysis states; but however, does not totally deny the role of unconscious determinants of behaviour. He equates these determinants to underlying BIOLOGICAL factors. According to Orubu, Sheldon further contends that the unconscious is the body. If individuals know more about the structure of their body and the biological factors at work within, they would be more conscious of the forces that impel their behaviour. Sheldon believes that there is much difficulty in verbalizing the unconscious because the individual's conscious language is not geared toward a systematic interpretation of what goes on in the body. Sheldon's work is aimed at understanding human behaviour directly and objectively through somatotyping.

\subsection{Sheldon's Theoritical Framework and Design on Personality}

His stance on personality is essentially an articulation and amplification of constitutional psychology, these are theories that suggest a relation between physique and behaviour.

Sheldon believed that there were three major Morphologies or body types: ENDOMORPHY, MESOMOPHY, and ECTOMOPHY. These will be explained clearly respectively as follows:

a. Endomorphy: The endomorph, during conception, in the womb, mass of cells develop three layers, the central layer, the endoderm or "inner skin" develops into the digestive system and internal organs; if it becomes dominant, the individual develops a Roly-poly spherical or endomorphic body and is fixed on food; that is to say that the highly developed nature of the digestive system accounts for the physique that emanates. Endomorphs has low specific gravity (low weight) and floats in water, their body is soft, with underdeveloped bones and muscles. People with such 
physiological qualities are very sociable, enjoys relaxing and lazing about, they are talkactive and prefers "the sweet life of physical comfort. Next is :

b. Mesomorphy: The middle layer of the mass of cell in the womb during conception known as the mesoderm turns into bones and muscles (McConnell, 1977), and if this mesoderm gains upper hand during foetal development, such and individual will build up a square mesomorphic body, which is strong, tough, resistant to injury. Infact a body generally equipped for strenuous physical demands predominantly characterized by strong bones and muscles Sheldon states that, the mesomorph likes sports and power game, they are energetic, assertive, courageous and sanguine.

c. Ectomorphy: Biologically, during conception, if the outer layer or Ectoderm comes out on top of the womb, the brain predominates and the body develops long, thin legs and arms and a large head. Hence; according to Sheldon, the ectomorphic individual is characterized by linear and fragile body, flatness of the chest and a thin slightly muscled body. The ectomorph has the largest brain and central nervous system in proportion to his size. He is over-exposed to external stimulation and is thus ill-equipped for vigorous and persistent physical activity. It is Sheldon's belief that the ectomorph is introverted, inhibited, and intellectual and prefers being alone rather than in a crowd.

Orubu, further states that Sheldon found that most of his subjects were not "pure" body types but mixtures, and then devised a seven-point scale for each of the three morphologies. The numerals run from 1 -7 with 1 representing the absolute minimum of the component and 7 the highest possible amount. The first of these numerals usually refers to endomorphy, the second to mesomorphy and the third to ectomorph.

A "true" endomorph would rate 7-0-0 but if the person were mostly an endomorph, then he or she might rate 6-1-1. A woman with some endomorphic characteristics and a little touch of ectomorph but mostly mesomorph would rate 2-5-1.

Sheldon further emphasizes on the constancy of the Somatotype, acknowledging that changes may be infused into the somatotype by way of aging process and diet, but contends in his earlier writing that, no nutritional change can cause the measurement $s$ of an individual in one somatotype to stimulate those of another somatotype. He asserts that there is the plausibility of nutritional factors producing changes in the individual measurements but these will not change the actual somatotype. Sheldon, according to Orubu , maintains that a starved mesomorph does not become an ectomorph, although remarkable changes may be produced by acromegaly and muscle wasting diseases.

\subsection{The Theory on Physique and Temperament}

Orubu (1987) in his work, futher pointed out that Sheldon, from his studies identified three primary components of temperament in relation to body or morphologies; as: Viscerotonia, Somatotonia and Cerebrotonia.

a. Viscerotonia: this component is closely related to endomorphy. An individual high in this component is characterized by general love of comfort, sociability and glutting for food, people and affection. Such an individual is relaxed in posture and movement, possesses a high degree of evenness of emotional flow, tolerance, complacency, love of polite ceremony and orientation toward childhood and family relationships. The personality seems to centre around the Viscera.

b. The second component is the Somatotonia: Closely associated with mesomorphy. A high score on this component indicates assertiveness of posture and movement, love of physical adventure, need and enjoyment of exercise, lust for combat, competitive aggressiveness, callousness toward the feelings of others, indifference to pain, noisy behaviour, extraversion, over maturity in appearance, claustrophobia and orientation toward goals and activities of youth.

c. Thirdly, Is The Cerebrotonia component which is associated with ectomorphy (Sheldon, $1942 \mathrm{p}$. 400). Scoring high on this component generally associates one with the quality of restraint, inhibition and the desire for concealment. The individual is secretive, self conscious, afraid of 
people and happiest in enclosed area; characterized by vocal restraint, hyper-attentionability, unpredictability of attitude, poor sleep habits, chaotic fatigue, youthful appearance, vertical mental cleavage, introversion, resistance to alcohol and other depressant drugs and orientation toward the later periods of life.

These three general dimensions together with twenty defining traits for each dimension, make up Sheldon's scale for temperament. Sheldon concludes that these measures will provide a frame of reference in terms of what psychology can contribute to the investigation of individual differences in the area of behaviour.
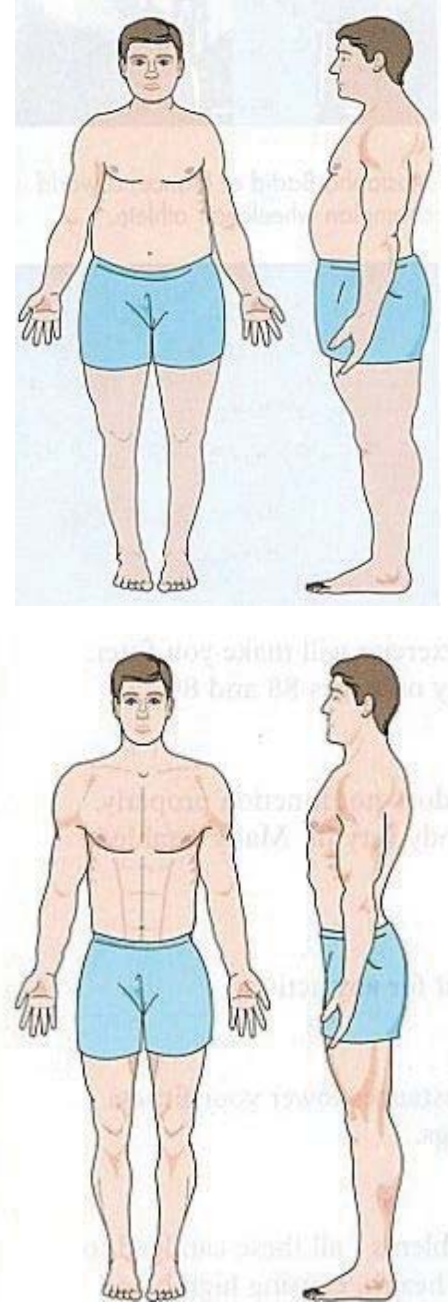

Endomorphic Body Type:

- soft body

- underdeveloped muscles

- round shaped

- over-developed digestive system

Associated Personality Traits:

- love of food

- tolerant

- evenness of emotions

- love of comfort

- sociable

- good humoured

- relaxed

- need for affection

Mesomorphic Body Type:

- hard, muscular body

- overly mature appearance

- rectangular shaped

- thick skin

- upright posture

Associated Personality Traits:

- adventurous

- desire for power and dominance

- courageous

- indifference to what others think or want

- assertive, bold

- zest for physical activity

- competitive

- love of risk and chance 


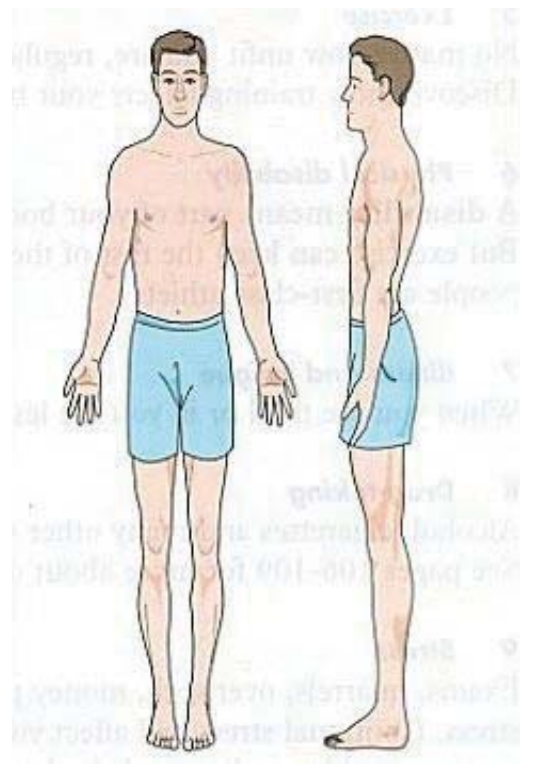
Ectomorphic Body Type:
- thin
- flat chest
- delicate build
- young appearance
- tall
- lightly muscled
- stoop-shouldered
- large brain
Associated Personality Traits:
- self-conscious
- preference for privacy
- introverted
- inhibited
- socially anxious
- artistic
- mentally intense
- emotionally restrained

Adapted from: Teaching clinical psychology - somatotypes(http://www.rider.edu/ $\neg$ suler/somato.html).

\subsection{Sheldon's inquiries}

\subsubsection{His Techniques}

Among the theories of personality, Sheldon's theory is quite unique, being that he emphasized genetic cause of behaviour, unlike most other psychologist who has remained on the environmental side of heredity (i.e. environmental theoretical speculation). Sheldon clearly tried to elaborate on how personality is affected by genetic endowment. He explains that it is possible to get some representation of personality factors through a definite set of measures based on the physique of the individual. He further stressed that biological structure (morphogenotype) that underlies the external observable physique (phenotype) plays a significant role in physical development as well as in the determination of behaviour. According to Orubu (1987), Sheldon adopted a taxonomic approach on the formulation of his constitutional theory of personality. His goal was to identify dimension on which physique could be classified; here he met with the major problem of how to get a large number of physiques which he could examine and re-examine; but he later devised a photographic technique, for practicality and efficiency, whereby he photographed the front and rear of individuals posed in a standard background. About 4000 college students were taken in the nude. These pictures were inspected by several judges with a view to identifying the major variables that formed the basis of physique variation.

\subsubsection{His Evidence:}

This Sheldon's postulation is that associating the body type and personality. It has been asserted that most of his investigations which were geared toward the testing of his theory fielded results that were indicative of a positive relationship between physique and behaviour. For example, Sheldon (1942) found a high correlation between Somatotype and temperament: endomorphy and viscerotonia, 0.79; mesomorphy and cerebrotonia, 0.82 ; ectomorphy and cerebrotonia, 0.83 . These correlations indicate that particular physical characteristics there are. 


\subsection{Some Criticism of Sheldon's Theory:}

A major criticism of Sheldon's work by psychologists is that he neither considers the age of his subject nor the socio economic environment that surrounded their growth (whether it was a poverty stricken one or a wealthy one) because McConnell (1977) observed that Korean orphans cared in the United States grew considerably larger and taller than their age-mates who remained behind in Korea in an impoverished environment. Judgement of individual personality was rated in morphological stereotypes rather than on observed behaviours.

Furthermore, Sheldon asserts that the somatotype he measures is a direct estimate of the genotype; if this measure of the body is genetically determined then identical twins should have perfectly correlated somatotype scores; but Lindzey (1967) found this otherwise, that these correlations were 0.36 for males and 0.61 for females. Also other investigators like, Lasker (1947) and Newman (1952) have found that the Somatotype changes significantly under environmental stress and even with age.

Moreover, Sheldon has suggested a high positive correlation between physique and temperament with a 0.83 correlation value, this, researchers have accused to have been inadvertently biased; Child (1950) who adopted a different rating method, whereby he gave questionnaires to his subjects instead of self-rating found his highest correlation to be 0.39 , a comparably different value; but be it as it may, there is still some significant relationship between body types and temperament.

Finally, though, even if we accept the assumption that there exist correlation between body type and temperament, it is still difficult to ascertain which of them causes the other. More so, Sheldon believes that the genetic blueprint determines both body shape and psychological traits; but there exist no correlational basis to establish anything about casualty by Sheldon.

In an additional note Sheldon's work lacks the completeness of application; it does not possess total Universal proof, because his scale for temperament was based on Euro-American culture and environment. It has no adaption to the African Culture and environment; hence this constitutes the significance of this study. It is the purpose of this study to specifically justify the culture - environmental applicability of Sheldon's theory on personality traits in Africa, using 242 students of the University of The Gambia(UTG),, The Gambia, West Africa as a case study, being that the university parades an international community of African students and faculty.

\section{Research Design}

A quantitative survey design was applied, with a validated 36 - item questionnaire. The questionnaire was administered to 242 (two hundred and forty two) University of The Gambia students by stratified sampling technique based on body types (whether endomorph, mesomorph or ectomorph) from the two campuses (Brikama and Kanifing). The questionnaire respondents were kept anonymous, due to the sensitive nature of information required of them. The questionnaires were made up of two sections. Section A, sought to indicate the body type possessed by the individual student (they included teenagers and adults). Section B, required a response of their peculiar personal behavioural or personality characteristics based on Sheldon's constitutional theory.

The coded responses from both sections were collated and correlated using the 2-tailed, Pearson's product-moment correlation coefficient $(r)$, to test the null hypothesis 1 , at $(a=0.05)$. The second null hypothesis, was tested using the 2-tailed t-test $(\alpha=0.05 ; \mathrm{df}=\infty)$, to determine if there exist any significant difference between the responses obtained for body types and personality traits of the individual.

\section{Findings/Discussion}

The following table below presents a summary of the findings based on Pearson's product-moment 
correlation analysis to test if any significant degree of relationship exists between the body types and personality trait of an individual within the African community; and also to measure, if there is therefore any significant difference between these variables using the 2-tailed,paired t- Test

\begin{tabular}{|c|c|c|c|c|c|c|c|}
\hline \multicolumn{2}{|c|}{ MODE } & \multicolumn{2}{|c|}{ MEAN } & \multicolumn{2}{c|}{ STDEV } & $\begin{array}{c}\text { CORRELATION } \\
(\mathrm{a}=0.05 ; \mathrm{df}=\infty)\end{array}$ & $\begin{array}{c}\text { T-TEST } \\
(2 \text {-tailed,paired } \\
(\mathrm{a}=0.05 ; \mathrm{df}=\infty)\end{array}$ \\
\cline { 1 - 5 } $\mathrm{X}$ & $\mathrm{Y}$ & $\mathrm{X}$ & $\mathrm{Y}$ & $\mathrm{X}$ & $\mathrm{Y}$ & $\begin{array}{c}0.448 . \\
\mathrm{HO}_{1}=\text { Rejected }\end{array}$ & $\begin{array}{c}1.266 . \\
\mathrm{HO}_{2}=\text { Accepted. }\end{array}$ \\
\hline 0.75 & 0.54 & 0.72 & 0.54 & 0.15 & 0.13 &
\end{tabular}

Table 1: Summary of the measures of central tendency, standard deviation of the body types and personality trait, respectively of 242 UTG students.

Correlation coefficient and T-Test measures of the body types Vs personality trait of 242 UTG students.

$X=$ Body Types (Endomorph, Mesomorph and Ectomorph) of 242 UTG students.

$Y=$ Personality or behavioural Traits of 242 UTG students.

For Hypothesis one: $\mathrm{HO}_{1}(\mathrm{P}=0 ; \alpha=0.05), \mathrm{r}$ varies from 0.00 to \pm 1.00 this implies that 0.00 to $+1.00=$ positive correlation $; 0.00$ to $-1.00=$ negative correlation. In this study the result calculated was $r=0.448$ which indicates a MODERATELY positive linear relationship or correlation between body types and personality traits of Africans. Therefore the null hypothesis which stated that, there is no significant relationship between body types and the personality or behavioural traits of individual Africans, was rejected. Hypothesis two: $\left(\mathrm{HO}_{2}: \mu_{1}=\mu_{2} ; \mu_{2}-\mu_{1}=0, \mathrm{df}=\infty\right)$, which stated that, there is no significant difference between body types and the personality or behavioural traits of individual Africans. In this case the analysis result shows that the $t$ value for the two - tailed test is 1.266, these values are more than the $a=0.05$ (significance level at $95 \%$ ), and the $t_{\text {obtained }}=1.266<t_{\text {critical }}=1.960$ which implies that the hypothesis is tenable, then we fail to reject . In this case also, since Ho: $\mu_{1}=\mu_{2} ; \mu_{2}-\mu_{1}=0$ at $\alpha=0.05$, and the $95 \%$ confidence intervals of -1.960 and +1.960 contain 0 .It is therefore concluded that the Null hypothesis will be true and thus accepted (Agresti. A and Barbara.F, 1999).

The physical body type an individual possesses has an influence on the behaviour or personality of that individual, as posited by Sheldon's constitutional theory. This has been confirmed even when applied in the African society. Though not very strong relationship is indicated by the study, this could be due to certain cultural and environmental influences on the African person, who are sometimes limited by their cultures, not to expose completely their character or behavioural make-up at the first instance, especially in response to written documents, to "strangers". So some tend to give responses that may not actually be the whole truth about their personality, rather than turn the Questioner or "Stranger "away, which may be viewed as impolite.

\section{Practical Application / Recommendaton Based on this Study of Sheldon's Theory and Conclusion}

As has been indicated earlier, Sheldon's constitutional psychology has received a great deal of vehement criticisms. Despite these criticisms, some aspects of the theory may be of great significance to psychologists and Educators, even lay individuals.

First, Sheldon's somatotyping would be an important tool to counsellors and teachers, because knowledge of the theory may be utilised in making intelligent guesses about personality of their students or clients. Also, Headmasters, form masters and House masters need to possess and understanding of the personality of their students. Sheldon's constitutional theory provides a repertoire of such knowledge.

Secondly, teachers who work in secondary and post secondary schools, may use some aspects of Sheldon's theory in their daily work, for example, a fragile ectomorphic individual, may not be assigned to perform vigorous physical and manual duties. 
Thirdly, due to the fact that individuals want to relate well to the other harmoniously, knowledge of Sheldon's theory may provide some clues as to the temperament of the individual in question; because according to Sheldon's theory fat people are jovial and tiny people are relatively secretive, which was further confirmed by the result of this study, irrespective of the cultural bias and the environment.

Fourthly, there are several expectations and behaviour associated with different types of physique, as has been found by Sheldon, so the knowledge of these behaviours would guide the Teacher's manner of interaction with different individual learner.

Finally, it is recommended that similar study be carried out in other regions in the Africa and from timeto- time, to totally ascertain its applicability and if it is time-bounds due to certain arising intervening variable or timeless as the case may be.

Sheldon has really distinguished himself as a constitutional psychologist, with his simple and specific theory; in contrasts to other personality theories, which provide a galaxy of blank spaces, Sheldon has identified a discrete number of physical and temperamental variables that are of primary importance in representing human behaviour. His work has stimulated a new attitude on the part of psychologists towards constitutional theories. However, as result of this study, it has been notably shown that Sheldon's constitutional theory DOES not entirely apply to every individual, cultures and environment.

Therefore the research concludes that the theory could be culture -and environment- bound or limited. By and large, this research work has positively ascertained to an appreciable degree, Sheldon's work on the individual personality; especially its adaptation to other cultures, specifically the African (society) culture and Environment, since human behaviour is culture and environment bound, undoubtedly.

\section{References.}

Agresti. A and Barbara .F (1999), Statistical methods for social sciences, 3rd ed., and p.216

Child, I.J. (1950), The relation of Somatotype to Self-rating on Sheldon's temperament traits. Journal of Personality, 80.

Hall, Calvin S. Lindsey, Gardner, (1957). Theories of personality, (pp. 336-377). Hoboken, NJ, US: John Wiley \& Sons Inc, xi, 572 pp. doi: 10.1037/10910-009.

Healey, F.J. (2009), STATISTICS:A tool for Social Research,8th Ed.,Wadsworth Cengage learning.

Igharo, O.K, (2013): EDUCATION: Measurement and Evaluation, Basic Research methods and Statistics, Banjul, Kenjam Educ. and professional publishing.

Lasker, G. (1947) The effects of partial Starvation on Somatotype: an analysis of material from the Minnesota Starvation Experiment. American Journal of Phys. Anthropology, 5, 323-341.

Lindsey G. (1967) Behaviour and Morphological Variation in J.N. Spuhler (Ed) Genetic Diversity and Human Behaviour. Chicago: Aldine.

McConnel, J.V.( 1977) Understanding Human behaviour. New York: Holt, Rhinehart and Winston,.

Newman, R.W. (1952) Age Changes in body build. American Journal of Phys. Anthropology, , 10, 79-90.

Orubu, A.O. (1978) The Constitutional approach by W.H. Sheldon in A UBA (Ed) Theories of Personality. Ibadan, Claveranium Press, , pp. $111-119$.

PsycINFO (2010) Database Record (c) American psychological Association. 